\title{
The Group Coaching Conundrum
}

\author{
Manfred F. R. Kets de Vries, INSEAD, 77305 Fontainebleau Cedex, France \\ Contact Email: manfred.ketsdevries@insead.edu
}

\begin{abstract}
This article sheds light on the challenges facing coaches when undertaking the journey to becoming a group coach. It begins with observations on the state of the art of group and team coaching and continues with a description of the various conundrums faced by coaches interested in pursuing this kind of activity. Subsequently, it describes a coach's reflections on leadership group coaching and shares his inner journey toward becoming a group coach. The second part of the article reflects on what makes group coaching an effective intervention, discussing the dynamic processes applicable to individual participants and the 'cloud issues' or themes that the group-as-a-whole brings to the table. It describes seven premises that characterize the clinical paradigm, a psychodynamic lens that can be turned on our inner theatre. The article also highlights a number of other psychodynamic processes that take place during the group coaching process, creating tipping points for change.
\end{abstract}

Key Words: group coaching; clinical paradigm; Plato’s cave; tipping points; transitional space.

\section{Introduction}

You cannot teach a man anything. You can only help him discover it within himself. -Galileo Galilei

The greatest danger for most of us is not that our aim is too high and we miss it, but that our aim is too low and we reach it.

-Michelangelo

Those who have immobilized and muted many of the plots and players in their internal theatre, allowing them no action but to hammer on the walls of the mind, might learn to value the words of Sartre: "If you want your characters to live, then liberate them!"

-Joyce McDougall

There is a vast literature on group dynamics, teams and the roles people play in groups (Belbin, 1981; Jackson, 1992; Hackman, 2002; Hackman and Wageman, 2005; Yalom, and Leszcz, 2005; Kets de Vries, 2007; Wageman, Nunes, Burruss, and Hackman, 2008). Unfortunately, we cannot make the same observation about group and team coaching. Notwithstanding the many benefits that this kind of coaching offers to organisations, the literature pertaining to the topic is non-existent or scarce, and whatever is available has only been emerging very recently (Kets de Vries, 2005a, 2011; Clutterbuck, 2007; Britton, 2010; Thornton, 2010; Cockerham, 2011; Hawkins, 2012). A considerable part of the literature available tends to be of a public relationship nature, advertising the benefits of working with whatever coaching organisation has presented the information. This is regrettable, however, as group and team coaching (if done well) can take advantage of the collective wisdom of its participants through shared experiences, modeling, social contagion and interpersonal learning. To the participants, it is a great method to acquire shared objectives, become better at constructive conflict resolution, make stronger commitments and increase accountability; all factors that contribute to better results. Furthermore, as this form of intervention 
increases trust and reduces conflict, participants can achieve the required objectives by focusing on whatever the real work is that needs to be done. Thus, group and team coaching makes a highly effective way of creating tipping points for change. This form of intervention will be very apposite in today's highly complex, global, networking oriented organisations, which are characterized by great cultural diversity and virtuality (Driskell, Radtke, and Salas, 2003).

This article describes the conundrum that leadership coaches face when wanting to undertake the journey of becoming a group coach. For the purpose of illumination, a composite case history is used to demonstrate some of the important issues pertaining to this kind of intervention. The case presented illustrates what coaches are up against when undertaking this venture. This particular case discussion is presented in the context of coaching at INSEAD, the most global business school in the world (having campuses in France, Singapore, and Abu Dhabi). At this institution, given the cultural diversity of its clientele, effective working in teams is viewed as being of paramount importance. The first part of this article describes the case study of Peter's reflections on leadership group coaching, exploring his inner journey toward becoming a group coach. The second part of the article discusses what I believe makes group coaching such an effective intervention technique, exploring the dynamic processes applicable to individual participants, and the "cloud" issues - themes that the group-as-a-whole brings to the table.

\section{A coach's journey}

Peter had been asked to facilitate a group coaching session, unsupervised. For the first time he was going solo as a group coach, something he had looked forward to for a considerable time. So it was ironic that he felt so anxious. But one-on-one coaching is one thing; coaching in a group setting is a very different matter. It presented him with a conundrum - a number of puzzling questions. The way he felt now reminded Peter of how he had felt when he once took part in a fire walk. Taking the first step had been scary, but once he got the hang of it, the walk had been extremely exhilarating. To his great surprise he didn't get burned. Peter realised that going solo was another fire walk. Yes, he felt anxious-but he also felt exhilarated and curious. He was looking forward to the adventure. The session would be a milestone, the first step toward yet another role in his protean career. He should see it as the start of a new working identity.

\section{Becoming}

From the moment Peter had learned about coaching, he had been enthusiastic about it. As an executive, he had participated in various coaching interventions, and always found the coaches' insights extremely useful. He believed that coaching was a great way to help people deal more effectively with their professional and personal life. What better career can you have than one where you get the best out of people? What could be better than enabling others to make decisions that would improve the quality of their life? But there had been obstacles to overcome. Peter realised that if he was going to be effective as a coach, he had to deal with some issues of his own. To do this kind of work, he needed a healthy balance in his own life-and there had been times when his life had been completely out of sync. He needed to work on his relationships with people close to him, which meant working on his own emotional self-mastery. For Peter, overcoming fears, insecurity, and uncertainties had been a lifelong challenge. But Peter knew that nobody could make him feel inferior without his own consent. He needed to have greater clarity about why he wanted to become a coach before he embarked on this new career. He had to ask himself some searching questions.

\section{A state of being}

Peter asked himself a range of questions concerning his desire to become a coach. Was it about helping himself or was it about helping other people? To be an effective coach, he would have to be willing to leave his ego outside the door when dealing with others. Could he do that? Could he leave himself out of the picture, and step into another person's world? He knew he would only be able to function authentically as a coach if he could answer "Yes" to those questions. 
Peter also realised that he would have to be prepared to find out new things about himself, but was not sure he would like what he found. Knowing more about his conflicts, wishes, desires, fears, biases, and blind spots, however, was better than not knowing. It would prevent him from projecting his own biases onto his clients. Arriving at this level of self-understanding would not be easy, but it would make for an interesting journey. If he got things right, he would have a constant learning dialogue with his clients. Of course, this would entail a mutual willingness to share perspectives, the ability to truly listen to others, be open to new ideas, and take joint responsibility for the conversation and its outcomes. In fact, the coaching journey implied a lifelong quest for personal excellence. When Peter thought about this further, he realised that his own quest for greater self-awareness might have been his motivation to become a coach in the first place.

Peter was naturally empathic, had always been interested in understanding better the people he came across, and was very good at sense making. He knew he was highly skilled at listening not only to what other people were saying but also what they were not saying - at least verbally. It came naturally to him to listen with the third ear, and decipher the unspoken text behind the words. He had always paid attention to facial expressions, body language, tone of voice, and expressions of emotion. Perhaps Peter's ability to put himself in others' shoes (without necessarily agreeing with them) was one reason for these inner dialogues. It was his way of understanding better what others were doing to him. He knew how to use himself as an instrument (Kets de Vries, 2011). He was aware of his feelings, why he had certain feelings-and the impact he had on others. He was also very good at recognizing how others perceived him. These skills made it easy for him to build trustful, collaborative relationships with others, a sine qua non for an effective coaching relationship. But by using himself as an instrument, he also knew how to catch others off-guard. They would often be surprised when he shared his observations with them.

Peter realised that the journey to becoming a coach had contributed to his own internal change and growth. It had helped him to understand himself better and taught him to be more effective at connecting to other people. His contact with a great variety of people had helped him continue to learn and grow. Most importantly, taking this coaching journey had made him feel much better.

One of the valuable things Peter had learned in his development as a coach was to engage every day in a process of self-evaluation and self-reflection. He believed strongly that all coaches-indeed, anyone working in a helping profession-could profit from this reflective process. After all, we all have only so many days in our life. How else can we know whether a particular day has been useful? Peter also knew he could communicate hope and possibility to others-he was very good at identifying other people's strengths and getting the best out of them. His track record showed that he had been effective in helping many of the people he encountered.

With these capabilities, it is no wonder that many people had steered Peter toward the coaching profession. People had always come to him for advice. But Peter knew that being sought out for advice was only one part of the equation. He needed to learn how to help people act on that advice, once given. The value and contribution of coaching would be achieved through facilitation, not control, through asking the sort of open-ended questions that pushed people out of their comfort zone, confronting them with challenges, exploring options, and facilitating the discovery of new choices and possibilities.

Most people generally know (at least subliminally) the right thing to do when they find themselves in tricky situations. However, Peter had learned from experience that it was more effective if his clients figured out the answers that would work best for them. If he gave them the answer, they would be less likely to own the solution and fully commit themselves to it. Far too often, the people who came to Peter for advice played the helplessness card, unable to see the causal relationship between their choices, and the changes those choices would bring. Peter would point out to them that they had many choices and their

The current issue and full text archive of this journal is available at

http://business.brookes.ac.uk/ijebcm 
assumption that they had no control over their life was wrong. The challenge was to help them assume a different mindset.

Peter saw that interdependence and reciprocity were at the heart of the coaching process. Paradoxically, it is when we help others without any expectation of return that we invoke the power of reciprocity. It was largely a matter of timing. Going the extra mile for a client increased the client's sense of indebtedness and loyalty. And this was exactly the moment when the client would be more receptive to different ways of looking at once insoluble difficulties. But something more was required than good timing; the coach also needed to create a safe space in which the process could unfold.

Being aware of all these things was one thing, but applying them was another. Peter was conscious of his insecurity. Did he really have what it takes? He often felt that others were much quicker at picking up significant themes and identifying the major drivers in a client's life. Peter had always wanted to make a difference though and coaching offered that opportunity. He had seen it make a huge difference in other people's lives and he had figured out that by helping others improve the quality of their life and achieve their goals, he would feel better about himself. Now, contemplating his next step into solo group coaching, Peter knew there was a real basis to his feelings of anxiety. A leadership group coach has to earn credibility with every new intervention. Activity and achievement were very different things and should never be confused. Peter would have to gain the respect of his clients quickly and he would be under pressure produce immediate results, always an unrealistic expectation. Short-termism in a long-term setting could have worrying side effects.

\section{A state of doing}

Peter thought back to his first experience of a group coaching session, as a participant. Apart from his anxiety about what to expect, he had been nervous about what people would say about him. Most of the people he knew who had gone through a similar experience had been very positive about it; some said that, as a review of their leadership style, it had been one of the best learning experiences they had ever had. In the end, he had felt the same. With hindsight, Peter realised that that first group intervention had been the impetus for a number of important life changes, including becoming a coach himself. It had been a lengthy process. He started by enrolling in the specialized executive master program in coaching and consulting at INSEAD, which was longer than most. It had been an enlightening experience that involved two learning journeys. One was cognitive, learning more about psychological theory, career dynamics, leadership, family business, and organisational behaviour; the other involved an excursion-through an intense, personal psychotherapeutic intervention-into his own inner world. During the time in the program he learned an enormous amount about his strengths, weaknesses, personality, and drivers. It gave him the "AHA" experience that he had always wanted to be a leadership coach.

To prepare himself even better for this new adventure, Peter began to see a psychotherapist on a regular basis and enrolled in a clinical psychology program to improve his skills. To learn more about group behaviour, he participated in a few group dynamic events. Finally, he decided to leave the organisation where he had been working as head of talent management to start his own coaching practice.

With his network, it was not long before Peter had a fully booked coaching practice. But he realised he wanted to make a greater impact. To really influence the clients he worked with, and their organisations, he needed to become more familiar with group coaching - an intervention process that was both scary and exciting. Although he had become more familiar with group dynamics through various workshops, the next step was to understand group coaching better. Helped by people in one of the world's largest leadership development centres, he undertook a process of 'shadow' coaching - participation in a number of group coaching sessions under the supervision of experienced group coaches-a requirement for that institution for becoming a group coach. 
It became clear that group coaching was going to be a much more complicated challenge than one-onone coaching. Would he be able to handle the group dynamics? He would have to make insightful observations that would contribute to the success of the process-but how insightful was insightful? Peter took comfort from the fact that he had done his homework. He knew the bio-notes of the five participants by heart. He had read up on the company's values, culture, structure, strategy, and leadership. He had also studied carefully each participant's results from a 360-degree feedback instrument, the Global Executive Leadership Inventory (GELI), paying particular attention to the written comments by anonymous raters (Kets de Vries, 2004). Finally, he reflected on the outcomes of the Personality Audit (PA) (Kets de Vries, 2005b), another 360-degree multi-feedback instrument that listed the names of the people who had done the ratings. Peter noted that the comments made by close family members were, at times, extremely revealing.

When all the participants had arrived the coach did some introductions and explained why there was a shadow coach present. Peter was asked to say a few words about himself, which he did in rather humorously, despite his nerves. The coach then talked about the importance of confidentiality during the process, referring to the Hippocratic oath to "do no harm." She also pointed out the importance of time management-to ensure fair process, everybody should get an equal amount of time. To break the ice, the coach introduced an exercise in which each participant was asked to draw a self-portrait associated with themes such as head, heart, stomach, work, leisure, future, and past. They could use only symbols, no words. At first, the participants seemed uncomfortable about the assignment-some clearly thought it was childish - but after a little encouragement, and conscious that time was ticking by (they only had 20 minutes to complete the task), they got down to it. The self-portraits, with each participant's name attached, were then hung around the room.

It was time to start the group coaching process. The coach had already identified the participant she wanted to start with. She had explained to Peter that she had singled out someone with an 'average' dossier, that is, his ratings were neither extremely high—which could evoke envy—nor extremely low—which could make him embarrassed or defensive. The volunteer participant embarked full-heartedly on the exercise, setting an excellent example.

Before the session, the group coach had advised Peter to pay attention, not only to the person who was the subject of discussion, but also to the reactions of the group-as-a-whole. Their motto should be "Welcome the neuroses." Resistance should be seen as a sign that the coaching dialogue was on track and touching on important issues. She emphasized that working with client resistance, rather than trying to ignore it, or pushing it away, can help clients clarify their values and goals, and explore what will help or hinder them in making changes. An effective coach explores with clients (in a non-threatening way) what they don't want to hear, and makes them see what they don't want to see, so they can be what they have always known (at least, subliminally) they could be. But the coach also cautioned that it was important to "strike when the iron is cold." When the iron is too hot, the client may not be ready to hear what is said. As on many occasions, timing is everything. Often, it is can be better to keep your mouth shut even though interesting things are going on.

The shadow coaching day passed very quickly. One by one the participants took the "hot seat," starting with the self-portrait to point out highlights and lowlights in their life story, and received other people's reflections on the results of the GELI and PA. Peter saw how careful the coach was to deal with negative comments in a positive, sometimes humorous way-and how many positive comments were made to cancel one negative one. As the day went on, the participants began to feel more comfortable with each other. The atmosphere in the room became less tense, even playful, and Peter realised that he had become part of the play. Occasionally, he asked the person in the hot seat challenging questions, to prompt greater insight. During the day, a number of skeletons came rattling out of the closet; interpersonal conflict was discussed constructively; and ideas were put forward about how the company as a whole could improve its way of working. There was even a moderate amount of discussion of the company's values; in addition, 
structural themes such as organisational design were reviewed; and even a few strategic issues were put on the table.

By the time the coach summed up, everyone in the room had a clearer idea of the issues they needed to work on. They all now had a leadership action plan signed off by everyone else. The session had helped the group members get to know each other better, even though some of them had worked together for many years. In the coffee break, some told Peter that it was the first time the members of the team had held really courageous conversations. They seemed much less guarded and to be communicating more openly with one another. The session had helped resolve ongoing issues within the team that were becoming circular and frustrating. A number of the participants had been aware of some of these issues for some time, but never really done anything about it. The hope was that, this time, things would be different-no more short-lived New Year's resolutions.

To help them internalize their good intentions, the coach scheduled a number of conference calls during which they would discuss their progress, as well as a follow-up session where their action plans would be reexamined. In addition, each participant chose a "peer" coach from among the other group members whose task it was to keep them on track.

After the session, the coach reviewed Peter's contribution. She complimented him on his observations during the session and also explained why she had acted the way she did at certain times. She told him that she was very satisfied with the way he had handled his role as a shadow; how it had contributed to a successful experience for the group; and that she thought he would excel at this kind of work. She encouraged him to trust his intuition more and noted his ability to tolerate ambiguity and paradox, without having the urge to rush to closure. In short, she said, "You've got what it takes."

Afterwards, Peter realised that the coach had not said anything about the remarkable fact that after nine hours, a group of relative strangers had bonded, developed greater trust in one another, and were set to have a much better working relationship in the future. He reflected on how group coaching (especially in company-specific programs) could be an excellent way of making organisations strategically more agile. This was a great way to create a truly networked organisation and a highly effective way of minimizing the kind of paranoid thinking that was so likely to occur in virtual, highly diverse groups. A group coaching intervention could be a milestone in creating a 'boundaryless' organisation-one that would go beyond the silo mentality so prevalent in many complex organisations. From what he had witnessed he could see that this kind of intervention could lay the foundation for real information exchange. It once more dawned on him that setting up a data bank alone would not be enough to create a more agile, learning organisation. Unless the data were shared — by people who trust one another—nothing would really happen.

But why had all this happened? What was it about the process that made it so effective? How was it possible that the exchange of stories about the vicissitudes of five individuals' personal and professional life could, in such a short time, be a catalyst for change? It was really a conundrum.

\section{Learning from experience}

At INSEAD's Global Leadership Centre (IGLC), where the author pioneered the group coaching intervention method used in this case study, we have all been very agreeably surprised by its success. The outcomes have been much more impressive than we had originally imagined. The leadership coaches connected with the centre (and other institutions interested in the group coaching intervention process) have been delighted with the impact of this intervention method, which goes far beyond the creation of individual action plans, particularly for company-specific programmes. 
In its early days, the conundrum was that getting people working in the same organisations to talk about their life relatively intimately could have negative consequences; there was bound to be fear of selfexposure and lack of reciprocity, and possibly a variety of paranoid reactions. But concerns turned out to be unwarranted. Group coaching at INSEAD is a numbers game-by now more then 15,000 executives (from all over the world) have gone through the experience-and looking back at a long history of interventions, the problems encountered have been minuscule.

One extremely gratifying experience for the leadership coaches has been the participants' reactions. Very often, they have hailed the leadership group coaching intervention as the best thing that happened to them during an entire executive program. Even better, they complained that it had been too short. If the ratings and written feedback are to be believed, it seems to be an excellent learning experience for almost all the participants who have gone through the process. In many cases, the executives contact the coaches much later to thank them, saying how instrumental the event had been in creating a tipping point for making major career and life decisions. When the coaches would get together at the end of the day to discuss what had happened, often, they would express their surprise at people's revelations; they would talk about feeling privileged to help these people move forward in their life. However, I rarely used to hear them talk about why this particular process worked so well. Rarely was much insight provided about its dynamics.

Because I was very pleased with the results, for many years, I didn't explore the matter any further. Without really knowing what we were doing, we seemed to have stumbled on an intervention technique that proved extremely effective at creating inflection points in executives' lives. But after a while I started to feel uncomfortably dissatisfied. The reason why this process worked needed to be explored further. Were there elements of the design of the intervention process that made a difference? As I talked to many coaches about their experiences as a group coach I built up a composite experience and the case example of Peter can be viewed as representative of what happened to many of them.

\section{Sense-making}

When I started the group coaching intervention method on a larger scale, I would tell other leadership coaches that I didn't believe in a cookie-cutter approach to coaching. Although standardization has its advantages, I felt strongly that all coaches should approach group coaching in the way that best suited their personality; they should do what they were most comfortable doing. One recommendation I made (particularly in the case of very short interventions) was to use one or two multi-party feedback questionnaires to help jump-start the coaching process. The first is the Global Executive Leadership Inventory (GELI), which was developed at INSEAD and touches on the dimensions that most organisations list among their specific leadership competences. Another is the Personality Audit (PA), which combines feedback from people at work with feedback from partners, siblings, children, and close friends. Their feedback could have great emotional impact and become a tipping point for change. I also recommended ice-breaking exercises, like the self-portrait, which help create a safe space "to play" (Winnicott, 1958, 1971). I had always been interested in how Winnicott used the squiggle game, a pencil-and-paper technique he devised as a method of communicating with children to elicit their thoughts and feelings. The selfportrait was a logical continuation of this game. But apart from these suggestions, it was up to the coach to make the day a memorable learning experience.

\section{Plato's cave: the clinical paradigm}

I also strongly advocated applying the clinical paradigm to group coaching whenever appropriate. The clinical paradigm is a specific way of looking at human phenomena; metaphorically, it is a lens through which to explore people's inner theatre. To elaborate, many of the thoughts, feelings, and memories that float in a twilight zone between reality and fantasy; they may be blocked from consciousness and beyond our immediate awareness. The question becomes, how to bring these aspects of human functioning to the surface. I have found the clinical paradigm a highly effective way to go beyond the obvious and make them visible. It can help us understand better the irrational, sometimes darker aspects of personality functioning.

The current issue and full text archive of this journal is available at

http://business.brookes.ac.uk/ijebcm 
When the clinical paradigm is used as a conceptual framework to promote insight and change, people are made aware of a whole other world that co-exists with the world of reality and rationality - a world that may not yet be part of conscious awareness. Looking through this clinical lens helps us discover a world of fantasy, dreams, and daydreams, all representing forces that create another reality. Applying this lens adds a deeper and more nuanced understanding to intra-personal, interpersonal, group, and organisational phenomena.

Twenty-four centuries ago, Plato alluded to this twilight zone between reality and fantasy in his fable of the prisoners in the cave. In this story (found in The Republic), he presents one of the most famous images in the history of philosophy to illustrate how to differentiate between reality and fantasy. Plato compares most people to prisoners who are chained in a cave in such a way that they cannot turn their head. They are completely ignorant of the world beyond the cave and all they can see is the blank wall in front of them. Behind them, a fire burns and puppeteers walk between the fire and the prisoners holding up puppets that cast shadows on the wall of the cave. Because they know no better, and are unable to see the puppets passing behind them, the prisoners ascribe forms to the shadows.

According to Plato, the shadows are all the prisoners know of reality - a one-dimensional, shadowy appearance. However, if the prisoners were suddenly to be free of their chains, and could stand up, turn round and walk toward the fire, they would recognize the puppets and puppeteers as real and solid, even though before they had been only shadows. And when they left the cave altogether, and stepped into a new, exciting outside world, they would see colors and shapes. They would, literally, see the light and it would all make perfect sense. Unfortunately, if those prisoners who had seen the light went back to the cave to share their new knowledge with the others, they would find it difficult to explain what they had seen. Nobody would understand or believe them. How can the prisoners in the cave become aware of a world of light beyond the shadows they perceive? How can they be made aware of another reality?

The chained prisoners in Plato's cave are symbolic of the human condition. Most people are relatively ignorant about human behaviour and, like the prisoners in the cave, are comfortable with their ignorance, because it is all they know. Some however, are not satisfied to remain in this state. They want to penetrate the darkness. They want to be unchained, to turn their heads, and leave the cave. When we first begin to distinguish reality from illusion, it can be frightening, and because of this there will be always some people who prefer to stay chained and choose to remain ignorant. But most, once they discover it, opt for exploring a multi-dimensional life in glorious Technicolor.

In the context of leadership development, if we want to help people change their actions or behaviours, we need to step out of Plato's cave into the light. This is what happens when we apply the clinical paradigm. It helps us examine and reflect on our own behaviour, the behaviour of others, and the interrelationship between the two. We all possess a rich inner theatre, in which the key figures and experiences that influence the development of our personality take centre stage. The insights provided by a journey into that inner theatre could become stepping-stones to change.

The clinical lens consists of a number of premises:

1. It helps us understand that rationality is an illusion. Seemingly irrational behaviour is a common pattern in our lives, although it will always have a rationale, or meaning, to it. We need to become aware of the fact that very little of what we do is random. All aspects of our psychological makeup arise from specific causes or forces. Understanding the rationale about specific behaviour patterns is critical to making sense of our own and other people's inner theatre-the core themes (or script) that affect personality, behaviour and leadership style. 
2. To add to the mystery of human character, what we see is not necessarily what we get. Much of what happens to us is beyond our conscious awareness and unconscious forces drive most of our behaviour; this is not particularly comfortable to know. To have a better understanding of these unconscious patterns, we need to explore our own inner desires, wishes, feelings, and fantasies. But we also need to be prepared to take this inner journey.

3. We need to accept that we all have blind spots. There are many things we don't want to know about ourselves and we use various defensive processes and resistances to push these problematic thoughts away. However, many people derail (and take others with them) due to the blind spots in their personality. Exploring why we avoid distressing thoughts and feelings gives us a snapshot of our own personality and that of others. We need to accept that inner dissonance is part of the human condition.

4. The past is the lens through which we can understand the present and shape the future. All of us are the product of our past and there is continuity between the past and the present. We are inclined to view the present through the microscope of past experiences. Behind the curtain of the self, we all have a rich tragedy-comedy playing out on our inner stage, with key actors representing the people we have loved, hated, feared, and admired in our lives. Here we find memories and desires that are connected with emotions, some positive, some negative. As our personality structure depends on our genetic endowment and the developmental outcome of our early environment, to make sense of our behaviour we must explore our interpersonal history, including our original attachment relationships.

5. To gain a better understanding of others and ourselves, we need to identify the recurring themes and patterns that come up in connection with these key figures from the past, and explore any repetitive attempts to avoid distressing thoughts and feelings. To make sense of what makes us behave the way we do, we need to explore our interpersonal relationships. Adaptive and non-adaptive aspects of our operational mode will be affected by how our original attachment relationships - the relationships with our first caregivers-have evolved. These themes will be reactivated in the relationships we have with the people we deal with in the present. These transference or counter-transference reactions can be viewed as repetitions of relationships that were important in the past, but may now be acted out inappropriately in the present. They will affect our leadership style, the way we make decisions, and many other aspects of our work, as well as non-work-related parts of our lives.

6. Nothing is more central to who we are than the way we express and regulate our emotions. Our emotions shape and influence our identity and behaviour. Intellectual insight is not the same as emotional insight, which touches us at a much deeper level. Emotions play a vital role in shaping who we are and what we do. Paying attention to emotions is an essential part of transformational processes.

7. In addition, motivational need systems determine our personality. The motivational need systems that represent the interface of nature and nurture create the tightly interlocked triangle of our mental life (the three points of which are cognition, affect, and behaviour). Briefly, there are five basic motivational need systems, a number of which impact the workplace only peripherally. The first encompasses our physiological requirements, such as food, drink, excretion, sleep, and breathing; the second our need for sensual enjoyment and (later) sexual excitement; the third our need to respond aversively to certain situations through antagonism or withdrawal. In addition to these, there are two systems that impact the workplace directly and powerfully: the need for attachment/affiliation and the need for exploration/assertion. Our essential humanness is found in our need for attachment/affiliation -in seeking relationships with other people, and in striving to be part of something larger. The need for attachment drives the process of engagement with another human being; it is the universal experience of wanting to be close to another, to have the pleasures of sharing and affirmation. When this need for intimate engagement is extrapolated to groups, the desire to be associated with others can be described as a need for affiliation. Both attachment and affiliation play an emotional balancing act by confirming

The current issue and full text archive of this journal is available at

http://business.brookes.ac.uk/ijebcm 
our self-worth and contributing to our sense of self-esteem. The other motivational need system that is crucial for the workplace - the need for exploration/assertion - involves the ability to play, think, learn, and work. Like the need for attachment/affiliation, these needs begin early in life. Playful exploration and manipulation of the environment in response to exploratory-assertive motivation produces a sense of effectiveness, competency, autonomy, initiative, and industry.

Applying the clinical paradigm in coaching situations helped me to tease out the central interpersonal role in which clients consciously and unconsciously cast themselves. It also gave me an investigative method of identifying self-defeating expectations and negative self-appraisal, as well as outdated perceptions of the self. In coaching situations, I needed to make clients realise that what may have been effective behaviour at the age of 12 , could be highly destructive at the age of 40 . The clinical lens also enabled me to make sense of the prevailing group dynamics-the defensive patterns that manifested themselves within the group-as-a-whole.

Although the clinical paradigm was a great help in better understanding intra- personal, interpersonal and group dynamics, I started to wonder about other possible levers for change. What were some of the variables that made group coaching interventions such a success? What was the X-factor that group coaching provided? To help me better understand the process I embarked (with the help of a number of colleagues) on various research projects. I was trying to capture their intuitive knowledge of the coachesthe unknown knowns. The results of these projects were a series of edited books on coaching: Coach and Couch (Kets de Vries , Florent-Treacy \& Korotov, 2007), The Coaching Kaleidoscope (Kets de Vries, Guillen, Korotov \& Florent-Treacy, 2010), and Tricky Coaching (Korotov, Florent-Treacy, Kets de Vries \& Bernard, 2011) - books in which many coaches using the group intervention method reflected on their experiences. I also wrote The Hedgehog Effect (Kets de Vries, 2011) that focused on the dynamics of group intervention. My work on these four titles helped me to identify several forms of intercession that all of us had been practicing in the group coaching process.

\section{The power of groups}

Working in groups can be like navigating a way through a field of icebergs: much of the danger lies hidden below the surface. The iceberg is a very appropriate metaphor as it helps people visualize the overt and covert interpersonal dynamics that affect group work. While one-on-one coaching can be complex enough, the challenges become much more pronounced in a group coaching setting. The coach is constantly faced with conundrums. He or she has to digest and metabolize a myriad of dynamic, fluctuating and multidimensional projections that represent group members' intersubjective experiences at various developmental levels. If the group is going to progress (not regress), the coach needs to a safe container for all this emotional and cognitive debris and create an ambiance where participants can explore their feelings and challenges without the fear of judgment or rejection. The coach has to construct a safe, transitional space for the participants, where they have permission to talk about issues they never had the opportunity to confront before.

If this containment is satisfactory, the participants will be able to fully experience themselves, having found a space where the intolerable is tolerated. Such a safe space allows them to be in touch with all of what they really are in an honest and authentic manner. Being in such a safe space encourages participants to let go of previously repressed parts of themselves. It also makes them realise that their lives are not solely determined by fate, their personal history, or their genetic inheritance; it is also self-determined through their own free will. They have a say in the matter.

I have learned from experience that two dynamics occur simultaneously in group interventions. In the first place there are the dynamic processes applicable to the person in the hot seat whose life and career is being discussed. Simultaneously, there are also 'cloud issues' in the room-by this I mean the themes that the group-as-a-whole brings to the table (Kets de Vries, 2011), themes that as it were floating in the clouds.

The current issue and full text archive of this journal is available at

http://business.brookes.ac.uk/ijebcm 
Often these cloud issues remain untouched. However, I observed that some of the more sensitive (and more effective) coaches would address these cloud issues during a group session, when appropriate: this often happened when the group discussion seemed to have come to a halt. Cloud issues would usually involve the unfinished business of one or more of the participants, issues that had become contagious like envy, jealousy, lust, rivalry, fear of abandonment, shame, guilt, and fear of engulfment.

I began to realise other psychodynamic processes were taking place during a group coaching process, consciously or unconsciously-processes that produced tipping points for change. For example, if a relatively safe, playful space has been established, a number of things can occur:

1. A group or team intervention provides a context for cathartic experiences. For some members, a group is an audience as they get things off their chest; it can become a forum, at least figuratively, for emotional cleansing. Some participants are instrumental in bringing repressed feelings and fears to consciousness. Expressing the things that trouble us, instead of stubbornly holding them back, can be an extremely powerful emotional experience. However, proper containment of these emotions by the group coach and members of the group is essential to making such a catharsis a significant experience. However, there has to be a caveat here. Catharsis may not in itself have a beneficial effect. There are occasions when it can be counter-productive, in particular if it occurs at the wrong time or place. Under the right circumstances, however, it provides an opportunity to re-experience and transform deeply troubling or repetitive life experiences, helping an individual understand better why certain psychological wounds have been so troublesome. From psychotherapy research we know how important simple listening is in helping clients to move forward.

2. While listening to other people's life stories, participants may come to realise that they are not alone in their confusion and that others, too, struggle with similar problems. This realisation can bring a great sense of relief. The "join the human race" effect has great benefits. Mutual identification with specific problems offers many opportunities to discuss alternative ways of dealing with them.

3. Use of the clinical paradigm can set in motion a whole process of association about why the participants have been doing things in certain ways. Is that the only way? Is a behavioural repertoire that was extremely appropriate at one point in time, still effective now? Encouraged by the group members, these kinds of reflection can lead to a willingness to experiment in doing things differently and create new hope for the future. Participants realise that there are ways to get unstuck. In many instances, this kind of selfunderstanding and insight moves people a long way along the road to change.

4. Every presentation, not just their own, offers participants the opportunity for vicarious learning. They soon realise that learning does not only occur through direct participation in dialogue; they can also learn vicariously, by observing and listening to others' stories. This kind of learning implies retaining and replicating effective behaviour observed in others.

5. The interpersonal learning process can also be instrumental in detecting and correcting distortions in self-perception. There are always team members who are admired because of the way they deal with life's adversities. They become role models, the kind of people we would like to emulate. Imitative behaviouror identification with the other-is an important part of the interpersonal learning process and a force for change. Identification involves our associating with or taking on the qualities, characteristics, or views of another person or group. In this way we may assimilate an aspect, quality, or attribute of the other, and be transformed, wholly or partially, following the model the other provides. However, we need to be aware of the fact that identification is not necessarily a conscious process. 
6. Participants become a real community, members of a tribe that has gone through the same emotional experience. Tribes-people draw on a great deal of mutual support whenever one of them embarks on a new challenge. This feeling of social belonging can be a very powerful catalyst for change.

7. A group setting is also an opportunity to disseminate information about different aspects of human functioning. Occasionally didactic instruction by the leadership coach can be beneficial, although it should be given sparingly. Explanation, clarification, and even direct advice about certain events within the team can reduce anxiety, and establish a modicum of control when there is a troublesome problem. However, that it is not just the coach who will offer suggestions; members of the team will do the same. And here again, the process of vicarious experience can be very powerful. As I suggested before, it is inevitable that members of the group will find associations with their own situation in individual members' presentations. They might suggest taking a different approach and exploring other ways of going about things. Within the team setting, information can be shared about psychological problems, illness, and attaining a healthier work-life balance. By giving advice, they also help themselves and guidance activities can make the team function better.

8. A further positive force for change can be the altruistic motive, or the desire to put the needs of others above our own. While helping for helping's sake - the genuine desire to make things better for others - may seem selfless; ironically it can have some selfish side-effects. The act of giving to others can have numerous personal benefits. It feels good to be important to others, but more than that, there seems to be a link between being helpful to others, and living a longer, healthier, happier life. Helping others can have a therapeutic effect, contributing to our sense of self-respect and well-being. The initial rush from the 'helper's high' may be followed by a longer-lasting period of improved emotional health. Altruism prompts team members to credit fellow-members for having helped them to deal better with life's adversities. Learning through the influence of interpersonal relationships plays an essential role in making teams and individual members more effective. The willingness of team members to have courageous conversations with each other can be extremely illuminating. Team members are very well placed to point out others' dysfunctional character patterns. Offering to work on these with other members of the team can be a great incentive for change. Constructing our self-regard through the positive appraisals of others is an important component of learning.

Many of these psychological dynamics seemed to be contributing to the effectiveness of group coaching. In getting the process off the ground, however, much depends on the ability of coaches to use the clinical lens effectively and discreetly. They need to be very skilled at using themselves as instruments.

Many years ago, I was engaged in a research project that necessitated a visit to the island of Newfoundland in Canada. Just offshore there are a number of small islands that rise like citadels out of the sea and house millions of seabirds. Among these are the common murres, birds that fly quite fast but are not very agile due to their short wings; they move better underwater, and are excellent divers. Each female murre lays one egg on a tiny ledge of rock, hundreds or even thousands of feet above the sea. The ledges that form these breeding colonies are packed with murres, each pair guarding their one egg. After three weeks, the eggs hatch. Now the murre parents have a new challenge, feeding a chick that likes its fish fresh, not regurgitated. Four weeks later, the ledges are getting very crowded; it is clear there is no future there for the fledglings, who have literally to make a leap of faith. Encouraged by the parent birds below in the sea (they choose a time when it is almost dark so that they are safer from predators), the young murres are expected to jump off these high ledges, and become seafarers. I see a strong parallel here with group coaching. Like the murre parents, leadership group coaches need to help their clients get off that ledge, take a leap of faith, and create a better life. 


\section{References}

Belbin, M. (1981). Management teams. New York: Wiley.

Britton, J. J. (2010). Effective group coaching: tried and tested tools and resources for optimum group coaching results. New York: Wiley.

Clutterbuck, D. (2007). Coaching the team at work. London: Nicholas Brealey.

Cockerham, G.(2011). Group coaching: A comprehensive blueprint. Bloomington: iUniverse.com.

Driskell, J., Radtke, S. \& Salas, E. (2003). Virtual teams: Effect of technological mediation on team performance, Group Dynamics, 7(4): 297-323.

Hackman, J. R. (2002). Leading teams: Creating conditions for great performances. Boston: Harvard Business School Press.

Hackman, J. R. \&d Wageman, R. A. (2005). Theory of team coaching, Academy of Management Review, 30, (2), 269-287.

Hawkins, P. (2012). Leadership team coaching: Developing collective transformational leadership. London: Kogan Page.

Jackson, S. (1992). Team composition in organizations. In S. Worchel, W. Wood \& J. Simpson (Eds.), Group process and productivity (pp. 138-173). London: Sage.

Kets de Vries, M.F.R. (2004). The global executive leadership inventory: Participant's and facilitator's guide. San Francisco, Pfeiffer.

Kets de Vries, M.F.R. (2005a). Leadership group coaching in action: The zen of creating high performance teams, The Academy of Management Executive, 19 (1), 61-76.

Kets de Vries, M.F.R. (2005b). Personality audit: Participant guide and facilitator's guide. Fontainebleau, INSEAD Global Leadership Centre

Kets de Vries, M.F.R. (2007). Decoding the team conundrum: The eight roles executives play, Organizational Dynamics, 36 (1), 28-44.

Kets de Vries, M.F.R. (2011). The hedgehog effect: The secret of building high performance teams. London: Wiley.

Kets de Vries, M. F. R., Florent-Treacy, E. \& Korotov, K. (2007). Coach and couch: The psychology of making better leaders. Hampshire: Palgrave Macmillan.

Kets de Vries, M. F. R., Guillen, L., Korotov, K. \& Florent-Treacy, E. (2010). The coaching kaleidoscope: Insights from the inside. 'Hampshire: Palgrave/ Macmillan.

Korotov, K, Florent-Treacy, E., Kets de Vries, M.F.R. \& Bernard, A. (2011). Tricky coaching: Difficult cases in leadership coaching. Hampshire: Palgrave/ Macmillan.

Thornton, C. (2010). Group and team coaching: the essential guide. London: Routledge.

Wageman, R., Nunes, D., Burruss, J. \& Hackman, J. (2008). Senior leadership teams: What it takes to make them great. Boston: Harvard Business School Press.

Winnicott, D. W. (1958). Collected papers: Through paediatrics to psychoanalysis. London: Tavistock.

Winnicott, D. W. (1971). Playing and reality. London: Tavistock.

Yalom, I. \& Leszcz, M. (2005). The theory and practice of group psychotherapy. New York: Basic Books.

Manfred Kets de Vries is the founder of INSEAD's Global Leadership Centre. He has held professorships at INSEAD, McGill University, the Ecole des Hautes Etudes Commerciales, Montreal, Harvard Business School, and ESMT, Berlin. He is the Chairman of KDVI, a boutique strategic human resource development consulting firm. He is also a psychoanalyst, and the author of 35 books, and numerous scientific papers and case studies. 